\title{
A APLICAÇÃO DAS AÇÕES AFIRMATIVAS NO DIREITO AMBIENTAL
}

\author{
Erivaldo Cavalcanti e Silva Filho ${ }^{1}$ \\ Debora Bandeira Dias Koenow ${ }^{2}$
}

RESUMO: Este artigo tem por objetivo analisar o mecanismo de políticas de ações afirmativas no direito ambiental. Para tanto, por metodologia dedutiva com pesquisa bibliográfica, considera que ações afirmativas são instrumento de combate ao racismo enquanto meio de concretização do direito à igualdade material. Posteriormente, expostas diferenças entre racismo estrutural, institucional e individual e considerado o direito ao meio ambiente ecologicamente equilibrado como elemento para promoção da sadia qualidade de vida. Exposto ainda o conceito de racismo ambiental, como prejuízo de condições ambientais de grupos vulneráveis. Finalmente, delineada a aplicação das ações afirmativas no direito ambiental, promovendo justiça social e ambiental.

Palavras-Chave: Racismo; Direito Ambiental; Políticas afirmativas; Racismo ambiental; Políticas públicas.

\section{THE APPLICATION OF AFFIRMATIVE ACTIONS IN ENVIRONMENTAL LAW}

Abstract: This article aims to analyze the mechanism of affirmative action policies in environmental law.Using deductive methodology with bibliographic research, it considers that affirmative actions are instrument to combat racism as a means of materializing the right to material equality. Subsequently, differences between structural, institutional and individual racism were exposed and the right to ecologically balanced environment was considered as element to promote healthy quality of life. The concept of environmental racism is exposed, as a damage to the environmental conditions of vulnerable groups. Finally, the application of affirmative actions in environmental law is outlined, promoting social and environmental justice.

Key Word: Racism; Environmental Law; Affirmative policies; Environmental racism; Public policy.

\section{INTRODUÇÃO}

As ações afirmativas são instrumento de combate ao racismo, uma vez que através da motivada desigualdade de tratamento em determinadas temáticas, privilegia aqueles indivíduos pertencentes a grupos que são vítimas de racismo e discriminação, de modo a promover a igualdade material.

De fato, o racismo é objeto de estudo das mais diversas ciências humanas, como, por exemplo, a antropologia, a sociologia e o direito. Inclusive, a República Federativa do Brasil

\footnotetext{
1 Doutor em Desenvolvimento Sustentável e Mestre em Ciência Política. Coordenador e professor do Programa de Mestrado em Direito Ambiental da Universidade do Estado do Amazonas (UEA).

2 Mestranda em Direito Ambiental (PPGDA/UEA) da Universidade do Estado do Amazonas (UEA). Procuradora do Estado do Amazonas - PGE/AM.
} 
firmou compromisso através da assinatura da Convenção Interamericana de Direitos Humanos de combater o racismo, constando, dentre outras medidas, a de promoção de políticas públicas de ações afirmativas.

Considerando-se que o racismo é verdadeiro vilipêndio à dignidade da pessoa humana, tal manifestação odiosa atinge as mais diversas esferas da vida dos indivíduos. Dentre elas, o direito ao acesso ao meio ambiente ecologicamente equilibrado, previsto no art. 225, da Constituição da República e essencial à sadia qualidade de vida dos sujeitos.

O racismo ambiental apresenta-se como manifestação simultaneamente de injustiça ambiental e injustiça social, na qual grupos vulneráveis têm acessos desiguais a bens ambientais, tendo consequências negativas em sua própria saúde e qualidade de vida.

Assim, as ações afirmativas em direito ambiental traduzem-se em temática na qual políticas públicas em direito ambiental podem ser formuladas com o objetivo de, ao ressaltar a proteção ambiental a determinados grupos, ser possível promover a saúde e qualidade de vida de modo a enfrentar o racismo ambiental e promover igualdade material.

Destarte, dentre os objetivos deste trabalho está o de apresentar panorama quanto às ações afirmativas enquanto instrumento de combate ao racismo, conceituar o racismo ambiental e de analisar a aplicação das ações de políticas afirmativas no combate ao racismo ambiental. Justifica-se a abordagem da temática na contemporaneidade das problemáticas inerentes, em especial quanto à desigualdade social e desigualdade de acesso aos bens ambientais. Apresentar meios para lidar com essas questões e promover a igualdade material, uma das bases do Estado Democrático de Direito, é de suma importância.

Para o devido alcance dos objetivos do presente trabalho, aplicou-se a metodologia dedutiva, por meio de pesquisa de natureza documental, bibliográfica e integrativa, com o auxílio da internet, incluindo livros e revistas especializadas. Foram selecionadas obras, periódicos e legislação, os quais foram analisados na revisão de literatura ao longo do artigo.

\section{AS AÇÕES AFIRMATIVAS COMO INSTRUMENTO DE COMBATE AO RACISMO}

O racismo é uma manifestação que possui intersecção em diversos ramos da ciência. No tocante à antropologia, Guimarães (2004), parte da consideração da "época moderna, que começa com a geração de 1870, nas escolas de direito, do Recife e de São Paulo, e nas escolas 
de medicina, da Bahia e do Rio de Janeiro" (p.10) para conceituar o racismo brasileiro como uma reação à igualdade formal prevista legalmente e, sobretudo, como um movimento de reação das elites brasileiras de Salvador e Recife "às desigualdades regionais crescentes que se avolumavam entre o Norte e o Sul do país, em decorrência da decadência do açúcar e da prosperidade trazida pelo café" (p.11). Portanto, o racismo seria uma resposta àquele fato social.

Na obra "Casa Grande e Senzala", de 1933, Gilberto Freyre explicitou o papel do negro na formação da nação brasileira e apontou as mais diversas manifestações nas quais é possível identificar a direta participação do negro. Entretanto, Barros (2019) esclarece que Freyre apresentou o panorama de bases culturais do Brasil como se tivesse ocorrido uma harmônica miscigenação entre as três raças, contribuindo assim para o mito de que não haveria racismo no Brasil.

A ideia foi bastante difundida pela obra "Casa grande e senzala", escrita pelo sociólogo Gilberto Freyre, na década de 1930. Através da sua narrativa, Freyre descreve, a partir uma visão paternalista os atos "civilizatórios" dos portugueses, como a introdução/imposição da religiosidade, da língua e os costumes ao tempo em que os movimentos apresentam um imaginário do Brasil como um país ordeiro, progressista e cordial a partir da mestiçagem e da tolerância racial como foram processos naturalmente aceitos e harmoniosos entre as três as raças. (Barros, 2019, p. 35)

Quanto à percepção da sociologia, Resende (2008) pontua a baixa visibilidade dos conceitos de raça, racismo e etnicidade, frente à importância social destes fenômenos. Vieira (2010) afirma que o posicionamento do Supremo Tribunal Federal para o estabelecimento do conceito de raça não se limita à perspectiva biológica, mas sim à perspectiva sociológica de arranjos ideológicos no sentido de dominação de um grupo.

Clara fica a opção do STF por um conceito de raça proposto pela sociologia moderna que identifica o racismo como "tendência cultural decorrente de construções ideológicas e programas políticos visando à dominação de uma parcela da sociedade por outra". Assim, a palavra raça assume acepção de qualquer agregado de pessoas que possam ser identificadas - por seus traços culturais, sociais, dentre outros - como pertencentes a um certo grupo, podendo, em decorrência destas características, ser vítimas de ato de preconceito e discriminação. (p. 1774)

Pacheco et al (2013) esclarecem que a perspectiva ideológica do racismo tem raízes históricas que remontam o pressuposto europeu de que os indivíduos denominados como aqueles de raça branca seriam superiores. 
Considerando-se os conflitos e injustiças ambientais e seus impactos diferenciados sobre as populações desprivilegiadas, especialmente por suas características étnicas e raciais, propomos que, para o debate das questões socioambientais no Brasil, o racismo seja referido como ideologia e prática social baseada na hierarquização dos indivíduos e grupos sociais mediante sua racialização, que resulta em discriminação das raças consideradas inferiores. No processo histórico, especialmente de dominação dos povos pelos europeus desde o século XV, os indivíduos e os grupos ditos de raça branca foram considerados e tratados como superiores. E os modelos de desenvolvimento geradores dos conflitos e das injustiças não se eximem desses processos históricos. (Pacheco et al, 2013, p. 80)

Já no âmbito do Direito, o racismo é crime, cuja importância do desagravo é tamanha que previsto na Constituição da República ${ }^{3}$. Portanto, o combate ao racismo caracteriza-se como compromisso firmado pelo Brasil para a concretização do Estado Democrático de Direito através da proteção dos direitos fundamentais.

Inclusive, em 2013 foi subscrita pelo Brasil a Convenção Interamericana contra o Racismo. Através do Decreto Legislativo $1 / 2021^{4}$ a Convenção foi promulgada após ser submetida ao rito previsto no parágrafo $3^{\circ}$ do art. $5^{\circ 5}$ para que tratado internacional de direito humano goze do status de emenda constitucional, integrando o bloco de constitucionalidade como parâmetro para o exercício do controle de constitucionalidade.

Dentre as previsões da Convenção Interamericana contra o Racismo, no seu artigo cinco está o do compromisso dos Estados signatários de adotar políticas especiais e ações afirmativas para a garantia dos direitos fundamentais das vítimas do racismo. Neste dispositivo ainda está previsto que tais ações afirmativas não são discriminatórias, mas sim possuem o objetivo de promover condições equitativas para os indivíduos poderem gozar do direito à igualdade de modo substancial. No mais, tais ações devem ser feitas por tempo razoável até que alcancem os objetivos para o qual foram instituídas.

Flávia Piovesan (2008) afirma que a igualdade formal marcada na primeira fase de consolidação dos direitos humanos visa, sobretudo, a garantia de que os indivíduos percebam o outro como um sujeito de direitos, de modo que a alteridade seja garantia de reconhecimento da dignidade da pessoa humana a todos. Não obstante, a igualdade formal não garantiria o próprio núcleo do direito à igualdade. Isso em razão do fato de que a

\footnotetext{
${ }^{3}$ Art. $5^{\circ}$, XLII, CRFB/88 - a prática do racismo constitui crime inafiançável e imprescritível, sujeito à pena de reclusão, nos termos da lei

${ }^{4}$ https://www.in.gov.br/en/web/dou/-/decreto-legislativo-304416057

${ }^{5}$ Art. $5^{\circ} \S 3^{\circ}, \mathrm{CRFB} / 88$ - Os tratados e convenções internacionais sobre direitos humanos que forem aprovados, em cada Casa do Congresso Nacional, em dois turnos, por três quintos dos votos dos respectivos membros, serão equivalentes às emendas constitucionais.
}

CONPEDI LAW REVIEW | EVENTO VIRTUAL | v. 7 | n. 2 | p. 39 - 55 | JUL - DEZ | 2021 
supressão de direitos de alguns grupos de indivíduos e a inferiorização histórica de garantias impede que os indivíduos partam das mesmas oportunidades.

Portanto, necessária a observância do conceito de igualdade material, de modo que seja conferido tratamento diferenciado àqueles que não estão em situação que seja possível iguala-los. Importa ainda que o tratamento desigual conferido nesta hipótese deva ser adequado à desigualdade em tela, de modo que seja consentâneo com a promoção da igualdade substancial.

Neste sentido, Piovesan (2008) aponta que em face da vulnerabilidade de determinados grupos e reconhecendo que os indivíduos possuem suas idiossincrasias, a própria diferença de tratamento jurídico é veículo para a promoção da igualdade material.

\begin{abstract}
Torna-se, contudo, insuficiente tratar o indivíduo de forma genérica, geral e abstrata. Faz-se necessária a especificaçåo do sujeito de direito, que passa a ser visto em suas peculiaridades e particularidades. Nessa ótica, determinados sujeitos de direitos, ou determinadas violações de direitos, exigem uma resposta específica e diferenciada. Isto é, na esfera internacional, se uma primeira vertente de instrumentos internacionais nasce com a vocação de proporcionar uma proteção geral, genérica e abstrata, refletindo o próprio temor da diferença (que na era Hitler foi justificativa para o extermínio e a destruição), percebe-se, posteriormente, a necessidade de conferir a determinados grupos uma proteção especial e particularizada, em face de sua própria vulnerabilidade. Isso significa que a diferença não mais seria utilizada para a aniquilação de direitos, mas, ao revés, para a promoção de direitos. (p. 888)
\end{abstract}

Destarte, as ações afirmativas utilizam da própria diferença de tratamento para ser veículo da igualdade material, de modo que uma vez que não sejam mais necessárias possam ser extintas, pois já teriam cumprido a sua função e não seriam mais meio de alcançar o fim pretendido inicialmente. Então, neste estágio social, a própria igualdade formal já seria o suficiente para a garantia do direito à igualdade substancial.

Dos Santos (2018) aponta que dentre as diversas narrativas, prevalece a de que as ações afirmativas teriam surgido como fruto da conquista de direitos civis pelos negros estadunidenses da década de 1960. Conceitua Dos Santos (2018) as ações afirmativas como “políticas públicas (e também privadas) voltadas à concretização do princípio constitucional da igualdade material e à neutralização dos efeitos da discriminação racial, de gênero, de idade, de origem nacional e de compleição física" (p. 2112).

Importante ainda destacar que o autor ressalta que as ações afirmativas não têm por objetivo apenas o combate à exteriorização evidente da discriminação, mas também aos fatores que levam com que a mesma ocorra, de modo que a luta contra o racismo seja 
efetuada mais profundamente. Haveria verdadeiro caráter pedagógico na execução das ações afirmativas.

No Brasil, quanto às ações afirmativas de combate ao racismo, é paradigmática a adoção das cotas raciais para o acesso à universidade e a cargos públicos. O Supremo Tribunal Federal, através de decisão na Arguição de Descumprimento de Preceito Fundamental 186 e na Ação Declaratória de Constitucionalidade 41, decidiu pela constitucionalidade de tal medida. Portanto, privilegiada a persecução da igualdade material.

Em sede da Ação Declaratória de Constitucionalidade 41 foi firmado entendimento de que há respaldo constitucional na utilização das ações afirmativas de reserva de vagas em concurso público em razão do critério racial.

Já na Arguição de Descumprimento de Preceito Fundamental 186, de relatoria do Ministro Ricardo Lewandowski a decisão foi pela improcedência da ação que questionava a constitucionalidade da norma que prevê a reserva de vagas por critérios étnico-raciais para ingresso no ensino superior.

Assim sendo, uma vez que o racismo é vilipêndio ao direito à igualdade com a inferiorização do indivíduo em razão de uma característica que lhe é própria, as ações afirmativas, meio de promoção da igualdade material, apresentam-se como ferramenta de combate ao próprio racismo.

\section{RACISMO AMBIENTAL}

Estando o racismo e as práticas discriminatórias arraigadas nas mais diversas ações e comportamentos da sociedade, evidente a necessidade do combate de modo igualmente profundo para que a igualdade material possa ser estabelecida, de modo a haver campo para a promoção da dignidade da pessoa humana.

Batista (p. 2582, 2018) esclarece que o racismo seria uma discriminação sistemática em razão da raça dos indivíduos, gerando privilégios ou desvantagens dependendo do lugar do sujeito. Já a discriminação seria tratar alguém de modo desigual utilizando-se do fator da raça.

Dentre as espécies de racismo, cumpre destacar o racismo estrutural. Bersani (2018) propõe que o racismo estrutural seria aquele que está intimamente ligado com a própria constituição da sociedade brasileira. Ou seja, ele ultrapassa a exteriorização de atitudes 
racistas para ser arraigado na sociedade e em suas práticas. Por outro lado, o racismo institucional seria um conceito mais restrito do que o de racismo estrutural, uma vez que é aquele próprio das instituições. Bujato e Souza (2020) apontam ainda o conceito de racismo individual, que seria manifestação patológica e expressão individual de quem é racista.

Estabelecidas tais premissas, fica evidente que o racismo, seja ele estrutural, institucional ou individual manifesta-se nos mais diversos fatores sociais. Dentre eles, o direito ao meio ambiente ecologicamente equilibrado não passa incólume à incidência de fatores de discriminação racial.

O direito ao meio ambiente ecologicamente equilibrado é previsto constitucionalmente no art. $225^{6}$, da Constituição da República. Silveira (2018) ressalta que tal direito é caracterizado como direito fundamental de terceira dimensão, portanto calcado nos ideais de fraternidade e de solidariedade.

Importante destacar que tal classificação pressupõe que os direitos podem ser agrupados em dimensões que se relacionam com o bem protegido juridicamente. Os direitos de primeira dimensão são aqueles relacionados aos direito de liberdade, direitos classicamente relacionados a um comportamento de não intervenção estatal para a sua concretização. Já os direitos de segunda dimensão são os relacionados à igualdade. Exigem, portanto, comportamento ativo do Estado para a garantia de sua observância, sendo, portanto, eminentemente prestacionais. Já os direitos de terceira dimensão seriam aqueles ligados aos ideais de solidariedade e de fraternidade, no qual está inserido o direito ao meio ambiente ecologicamente equilibrado.

Dentre as peculiaridades, está a de que a titularidade do direito de terceira dimensão seria coletiva e não individual, como ocorre com os direitos tradicionalmente elencados.

Os direitos humanos de terceira dimensão ou geração que também podem ser chamados de direitos da fraternidade apresentam uma distinção importante frente as demais categorias dos direitos humanos, pois os denominados direitos humanos da fraternidade saem da lógica homem-indivíduo no que diz respeito a titularidade dos direitos e passam para a ideia de titularidade de grupos ou até titularidade difusa ou então coletiva (LAFER, 2001). Assim, nesses direitos de terceira dimensão, estão posicionados os direitos de titularidade coletiva, muitas vezes indefinida e indeterminável que ostenta como maior representante o direito humano ao meio ambiente, direito esse com características de proteção universal, titularidade transindividual que por muitas vezes exige esforços e responsabilidades em nível

\footnotetext{
${ }^{6}$ Art. 225. Todos têm direito ao meio ambiente ecologicamente equilibrado, bem de uso comum do povo e essencial à sadia qualidade de vida, impondo-se ao poder público e à coletividade o dever de defendê-lo e preservá-lo para as presentes e futuras gerações.

CONPEDI LAW REVIEW | EVENTO VIRTUAL | v. 7 | n. 2 | p. 39 - 55 | JUL - DEZ | 2021 
mundial para a efetivação dos mesmo (SARLET, 2015). (SILVEIRA, 2018, p. 136 e 137)

Ao definir "todos" como destinatário do direito ao meio ambiente ecologicamente equilibrado, o legislador constituinte direcionou de modo expresso a fruição deste direito sem qualquer desigualdade ou marca discriminatória. Ainda ressaltou ser o direito ao meio ambiente ecologicamente equilibrado essencial para a promoção da sadia qualidade de vida, portanto, intrinsecamente ligada ao direito à saúde e ao direito à vida.

O conceito de meio ambiente está previsto na Lei 6.938/81 a Lei da Política Nacional do Meio Ambiente. Em seu artigo $3^{\circ}$, I, é considerado o meio ambiente como "conjunto de condições, leis, influências e interações de ordem física, química e biológica, que permite, abriga e rege a vida em todas as suas formas". Portanto, o direito ao meio ambiente ecologicamente equilibrado seria o equilíbrio da regulação das interações que permeiam a vida.

Delineada a importância do direito ao meio ambiente ecologicamente equilibrado, que, como direito fundamental, sua proteção resguarda a própria dignidade da pessoa humana, cumpre analisar o conceito de racismo ambiental.

Para Herculano (2008), o racismo ambiental é conceito que "diz respeito às injustiças sociais e ambientais que recaem de forma desproporcional sobre etnias vulnerabilizadas" (p.16). Para tanto, o autor aponta que historicamente o racismo ambiental teria sido arguido em protesto por moradores negros de uma comunidade na Carolina do Norte, nos Estados Unidos, na década de 80. Os mesmos teriam se organizado contra a instalação que contaminaria o solo de sua residência.

Esse clamor por Justiça Ambiental começou a ser organizado nos Estados Unidos, como iniciativa de cidadãos e como campo teórico/acadêmico, depois do caso de contaminação química em Love Canal, Niagara, estado de Nova York. Lá, a partir de 1978, moradores de um conjunto habitacional de classe média baixa descobriram que suas casas haviam sido erguidas junto a um canal que tinha sido aterrado com dejetos químicos industriais e bélicos (LEVINE, 1979; LEVINE, 1982; GIBBS, 1998). Pouco depois, em 1982, moradores da comunidade negra de Warren County, Carolina do Norte, também descobriram que um aterro para depósito de solo contaminado por PCB (polychlorinated biphenyls) seria instalado em sua vizinhança. Data daquele ano o primeiro protesto nacional feito pelos afroamericanos contra o que chamaram de 'racismo ambiental'. (HERCULANO, 2008, p. 2 e 3$)$ 
Depois de deflagrado o racismo ambiental, a visibilidade desta situação ganhou o discurso de movimentos contra o racismo, que também aderiram ao combate ao racismo ambiental. De fato, a nomeação do racismo ambiental mostra-se de essencial importância para promover o destaque à situação de injustiça social e de injustiça ambiental existente na desigual repartição dos danos ambientais e da desigualdade no acesso aos bens ambientais, com o prejuízo do gozo ao direito ao meio ambiente ecologicamente equilibrado para todos.

Importante destacar que o direito à Justiça Ambiental é pressuposto para o respeito ao meio ambiente equilibrado. Não é possível que haja gozo deste direito de forma plena sem que ele seja acessível a todos. Afinal, o direito ao meio ambiente ecologicamente equilibrado tem titularidade difusa e como tal não é divisível em seu gozo.

Por 'Justiça Ambiental' entenda-se o conjunto de princípios que asseguram que nenhum grupo de pessoas, sejam grupos étnicos, raciais ou de classe, suporte uma parcela desproporcional das conseqüências ambientais negativas de operações econômicas, de políticas e programas federais, estaduais e locais, bem como resultantes da ausência ou omissão de tais políticas (Herculano, 2008,p.2).

Jesus (2020) aponta que a população negra é grupo vulnerabilizado quanto ao acesso às condições de saneamento, o que gera repercussões na saúde deste grupo. Afirma o autor que o racismo institucionalizado gera mecanismos de exclusão de grupos desprivilegiados ao acesso às políticas públicas e aos serviços públicos de qualidade.

Importante ainda analisar a utilidade do conceito de racismo ambiental. Silva (2012) afirma que apesar do conceito sofrer críticas relacionadas ao suposto estímulo à concepção de que haveria raças distintas, a mesma não prospera. Afinal, o conceito não está centrado na ideia de raça e sim na ideia de existência do racismo, fenômeno estrutural de expressão em diversas questões sociais, dentre elas o racismo ambiental.

Assim, não há que se falar em Justiça Ambiental sem imiscuir-se no combate ao racismo ambiental. Quanto ao Brasil, a prevalência do mito da democracia racial exige que sejam deflagradas as mais diversas situações de racismo de modo a haver discussão social e devida crítica para que se abra campo para a promoção da igualdade material.

Também os desastres ambientais que atingem especialmente população vulnerável e que sofre o racismo nas mais diversas formas, apresentam-se como forma de exteriorização do racismo ambiental. Meneghini et al (2021) promovem reflexão quanto ao desastre de Brumadinho de 2019 e sua relação com o racismo ambiental. Apontam os autores que a 
exploração ambiental realizada na hipótese vulnerou grupos marginalizados, que sofreram os impactos do desastre ambiental.

\begin{abstract}
O desastre ambiental ocorrido com o rompimento da barragem de rejeitos no município de Brumadinho (barragem de rejeitos da Mina do Feijão), bem como os seus impactos ambientais e sociais demandam uma reflexão em relação à disposição dos rejeitos da mineração e como as empresas mineradoras desenvolvem uma atividade extrativista-predatória ante o modelo capitalista de sociedade e sua perspectiva de desenvolvimento. (Meneghini et al, 2021, p. 94)

Portanto, verifica-se que a maior parte das pessoas que foram afetadas pelo crime ambiental praticado pela mineradora Vale S.A. não são brancas, o que revela que estamos diante de um caso típico de Racismo ambiental, como aqueles que ocorreram nos Estados Unidos há décadas atrás. Isso porque o fato de ter sido instalada uma barragem de rejeitos naquela região e, ainda, o descaso da mineradora e do governo local com os riscos e

os impactos ambientais, estão intimamente ligados ao fato de que aquela região é ocupada por um grupo discriminado: não brancos e de

baixa renda.

$\mathrm{O}$ caso traduz o conceito racismo ambiental, pois trata-se de um mecanismo pelo qual a sociedade capitalista desigual destina a maior carga dos danos ambientais do desenvolvimento às populações negras e de baixa renda. (Meneghini et al, 2021, p.101)
\end{abstract}

Ou seja, o risco ambiental no desastre em questão foi imposto a grupos vítima do racismo. Apontam ainda Meneghini et al (2021) que a abordagem da temática do racismo ambiental no Brasil deve passar pelo pressuposto das peculiaridades pátrias de verdadeira hipocrisia no combate ao racismo. Isso em razão das bases da sociedade escravagista cuja abolição foi tardia, frente aos demais países, e sem que houvesse meios eficazes de concretizar esta abolição.

No mais, afirmam os autores haver no Brasil o "“mito da democracia racial' segundo o qual o Brasil, devido ao alto grau de miscigenação, estaria livre de preconceitos raciais" (Meneghini et al, 2021, p.97). Não obstante, o racismo estrutural existente no Brasil evidencia a desigualdade material no acesso aos bens e oportunidades pelos cidadãos.

Também a desigualdade no acesso à Justiça e de busca à garantia do gozo do direito ao meio ambiente ecologicamente equilibrado, caracteriza-se como uma das expressões do racismo ambiental. Meneghini et al (2021) promovem análise crítica quanto à desigualdade no acesso à justiça com fundamento no racismo ambiental. Para tanto, partem da concepção de acesso à justiça pela via dos direitos. Afirmam os autores que o conceito clássico de acesso à justiça defendido por Cappelletti e Garth, quanto aos obstáculos para acesso ao Poder Judiciário para a resolução de demandas e a proposta de "ondas de acesso à Justiça", abriu 
espaço para reflexão quanto ao fato de que o "acesso à justiça passou a ser considerado multifacetado, podendo ser analisado tanto de um ponto de vista social, quanto jurídico" (p. 98). Quanto ao aspecto jurídico poderia ser dividido o acesso à justiça na abordagem formal, que seria aquela defendida por Cappeletti e Garth de acesso ao Poder Judiciário para a submissão de lides. Já o aspecto material seria a própria garantia de efetividade dos direitos (Meneghini et al, 2021).

Expostos tais contornos, importa destacar que o racismo ambiental evidencia a desigualdade no acesso à justiça não apenas de modo formal, mas também material. Afinal o acesso ao direito ao meio ambiente ecologicamente equilibrado é desigual e prejudicado de modo mais intenso em grupos sujeitos ao racismo nas mais diversas exteriorizações.

\begin{abstract}
É justamente nesse sentido que as injustiças ambientais, ou mais especificamente, o racismo ambiental é agravado, pois verifica-se que as classes populares e as minorias raciais têm menos condições de realização da sua cidadania, pois encontram espaços reduzidos de participação e, consequentemente, têm menos condições de fazer frente ao sistema capitalista que impõe o desenvolvimento de atividades nocivas ao ambiente e à saúde em locais próximos de onde vivem suas comunidades, o que representa um obstáculo ao acesso à justiça via direitos, que vai além do acesso ao judiciário. Ressalte-se que mesmo o acesso à justiça em sua acepção mais simples e formalista, como o acesso ao judiciário, também é dificultado para esses grupos, visto que o judiciário impõe uma série de barreiras formais (como custas processuais elevadas), sociais e culturais, que atingem sobretudo as minorias raciais e sociais. (p. 98 e 99, MENEGHINI et al, 2021).
\end{abstract}

Portanto, não havendo acesso igualitário ao direito ao meio ambiente ecologicamente equilibrado e sendo tal diferenciação feita com bases racistas, fica delineado o racismo ambiental. Tal prática é atentatória aos princípios do Estado Democrático de Direito, demandando combate através de políticas públicas, dentre as quais as ações afirmativas.

\title{
4. AÇÕES AFIRMATIVAS NO ÀMBITO DO DIREITO AMBIENTAL
}

Ressaltada a importância das políticas de ações afirmativas no combate ao racismo e exposto o conceito de racismo ambiental, cabe adentrar na questão da proposta de utilização das políticas de ações afirmativas para combate propriamente ao racismo ambiental.

Dos Santos (2018) apresenta histórico das ações afirmativas no Brasil apontando que na década de 1980 emergiu processo que culminou com o florescimento das ações afirmativas dos anos 2000. Apesar de reconhecer que o movimento antirracismo no Brasil remonta o período da escravatura, o autor afirma que na década de 1980 o Movimento Negro ganhou 
contorno relevante sob o cenário de redemocratização do país em face do regime ditatorial. A participação popular e movimentações políticas juntaram-se à valorização da cultura negra para o país. Seria a primeira geração dos movimentos antirracistas prévios à profusão das políticas afirmativas.

Por sua vez, a segunda geração é datada do final da década de 1980 e relaciona-se à tipificação penal da injúria racial e criminalização da discriminação racial. Já a terceira geração seria de meados da década de 1990, cuja centralidade seria o combate ao racismo através da edição de políticas públicas e de ações afirmativas. Dentre as matérias objeto de abordagem pelas políticas públicas deste período, Dos Santos (2018) elenca a habitação e o saneamento básico, matérias diretamente relacionadas ao direito ao meio ambiente ecologicamente equilibrado. Evidente, portanto, a adoção das ações afirmativas na seara do direito ambiental. Aqui ganha força "o combate aos impactos sociais do racismo e o racismo institucional" (Dos Santos, 2018, p. 2103 e 2104).

Dentre as hipóteses de concretização das ações afirmativas no direito ambiental, a proteção do direito à moradia digna tem grande relevância. Pacheco et al (2013) apontam que a exteriorização de poder e de privilégios está diretamente ligada à ocupação dos territórios, levando com que os grupos vítima de racismo sejam marginalizados. Portanto, também o acesso aos bens ambientais resta precário. Inclusive, remontando ao surgimento do conceito de racismo ambiental nos Estados Unidos da década de 80, os autores apontam para a importância da percepção de que a submissão exacerbada dos grupos discriminados a riscos ambientais era proposital.

Nesse contexto, as denúncias das 'lideranças de cor' deixavam bastante evidente que não era (e ainda não é) fortuito, mas intencional, o fato de o Estado e as empresas poluírem prioritariamente seus locais de moradia ou de negarem às populações 'não brancas' as políticas necessárias para uma qualidade de vida realmente digna (Pacheco et al, 2013, p.88)

Já Barros (2019) utiliza o exemplo do Parque Santana Ariano Suassuna em Recife para abordar a deflagração do racismo ambiental no direito ao lazer. A autora conclui que os parques públicos não atendem à população de modo igualitário, colocando à margem aquelas que sofrem racismo. Exemplificativamente, ao lado do direito à moradia, tal hipótese de racismo ambiental no âmbito do direito ao lazer também se apresenta como campo para a promoção de políticas afirmativas de atenção especial aos grupos vítimas de racismo ambiental, de modo que haja a promoção da igualdade material. 
A abordagem sobre espaço, território, política e poder nas relações étnico raciais no Estado moderno, nos apresenta fontes para a discussão sobre o papel do Estado frente a desigualdade e sobre como esta, não é provocada apenas por fatores econômicos de distribuição de renda, mas traz em seu âmago fatores hegemônicos culturais e principalmente raciais, contidos nas diferentes escalas do espaço. (BARROS, 2019, p. 51)

Portanto, a promoção de direitos fundamentais ligados ao direito ao meio ambiente ecologicamente equilibrado a grupos que sofrem o racismo ambiental de modo prioritário permite a concretização do direito à igualdade material na seara. Assim, através da edição de políticas públicas preferenciais a este grupo, possível a promoção da Justiça Social e Ambiental.

Em pesquisa promovida por Novaes e Bryan (2015), foi questionado aos professores e funcionários do Instituto Federal de Educação, Ciência e Tecnologia de São Paulo (IFSP) se nas funções ou disciplinas sob a responsabilidade destes profissionais temas como políticas afirmativas ou questões ambientais estavam sendo trabalhados. Caso a resposta fosse negativa, perguntava-se o motivo. A conclusão foi a de que apesar de $46,6 \%$ dos professores da instituição afirmar que trabalhavam com questões ambientais, apenas 17,5\% trabalhavam com temáticas relacionadas a políticas afirmativas.

Interessante é destacar nos fundamentos da pesquisa o pressuposto de que "a legislação educacional brasileira harmoniza a defesa do meio ambiente com justiça social para uma vida humana sustentável” (NOVAS E Bryan, 2015, p. 15). Ou seja, a justiça social é pressuposto para o desenvolvimento sustentável. Assim, a promoção de políticas afirmativas com respeito ao meio ambiente precisa ser promovida também no âmbito educacional.

Jardim e Calloni (2020) também ressaltam a importância da educação ambiental e conferem a ela o papel de promover transformação social. Apontam que deve a educação ambiental ser crítica de modo a gerar reflexão quanto ao papel do indivíduo na promoção do desenvolvimento sustentável frente ao cenário que o permeia. A partir da perspectiva da educação ambiental crítica, os autores destacam as ações afirmativas como meio de promoção da sustentabilidade.

As Ações Afirmativas se constituem numa perspectiva de emancipação do sujeito, em que a busca da superação da relação contraditória opressor-oprimido, consiga atingir uma nova ordem social, construída em conformidade com a liberdade e igualdade. Dessa forma, o que as Ações Afirmativas buscam garantir é o desenvolvimento integral do humano, que consequentemente desenvolve $o$ 
crescimento local e global em todos os aspectos que possamos imaginar (Jardim e Calloni, 2020, p.12).

Percebe-se assim que a partir da educação ambiental permeada pela diretriz de reforço das ações afirmativas enquanto instrumento de combate ao racismo é possível a promoção do meio ambiente ecologicamente equilibrado, direito este que só é garantido quando para todos, independente de qualquer característica física, social, ou de qualquer outra ordem.

\section{CONCLUSÃO}

As políticas públicas de ações afirmativas no direito ambiental são meio de promoção de igualdade e justiça social que partem do pressuposto de que a diferença de tratamento entre os indivíduos para favorecimento daqueles grupos que sofrem racismo é instrumento de consolidação da igualdade material.

De fato, o racismo é conceito dotado de interdisciplinaridade e exige atenção dos mais diversos campos das ciências humanas para análise e enfrentamento desta situação de desprestígio de determinados grupos no gozo de seus direitos. Dentre os marcos de instrumentos legislativos de combate ao racismo, importante é a subscrição pelo Brasil da Convenção Interamericana contra o Racismo, em 2013.

Portanto, a atenção privilegiada aos grupos que sofrem o racismo passa por valorizar tanto a educação ambiental crítica como prestigiar na promoção de políticas públicas para assegurar o direito ao meio ambiente ecologicamente equilibrado de modo mais acentuado em face dos indivíduos pertencentes aos grupos que já sofrem discriminação.

O racismo ambiental é conceito cuja reflexão remonta movimento dos Estados Unidos da América, da década de 80 na defesa de grupos negros do direito à moradia com o respeito ao meio ambiente ecologicamente equilibrado. No Brasil tornou-se campo essencial de análise crítica de modo a combater o mito da democracia racial. Deflagrado, portanto, o racismo ambiental em situações cotidianas e na emergência de desastres ambientais, fica evidente a necessidade da especial atenção de políticas públicas voltadas a estes grupos para a promoção da igualdade material.

A observância do direito ao desenvolvimento sustentável é de essencial relevância para a promoção da saúde e qualidade de vida dos indivíduos e como tal é essencial para a observância da dignidade da pessoa humana. 
Levar em consideração o racismo ambiental na edição de políticas públicas voltadas à proteção ao meio ambiente é essencial para a atuação estatal de modo consentâneo com a realidade social. Nesse sentido, frente à desigualdade social e ao racismo existente também na fruição dos bens ambientais, as ações afirmativas são ferramentas para promoção de igualdade material ao acesso ao direito ao meio ambiente ecologicamente equilibrado.

Exemplificativamente, a promoção ao direito à moradia e ao direito ao lazer apresenta-se como campo fecundo à edição de políticas afirmativas de especial atenção a grupos vítima de racismo ambiental com vistas à concretização da igualdade material também de gozo do direito ao meio ambiente ecologicamente equilibrado.

Enquanto direito fundamental de terceira dimensão de titularidade da coletividade, não há que se falar em meio ambiente ecologicamente equilibrado sem o acesso a todos a este direito. Justiça Social e Justiça Ambiental relacionam-se e promovem a um só tempo os ideais de Justiça preconizados na Constituição pátria, que adota o Estado Democrático de Direito, promovendo a sadia qualidade de vida e a dignidade da pessoa humana.

\section{REFERÊNCIAS}

BARROS, Juliane de Lima. Racismo ambiental e direito ao lazer no espaço público: um estudo sobre o Parque Santana Ariano Suassuna. 2019. Dissertação (Mestrado em Desenvolvimento Urbano) - Universidade Federal de Pernambuco, Recife, 2019. Disponível em: https://repositorio.ufpe.br/handle/123456789/39968. Acesso em 03 out 2021.

BATISTA, Waleska Miguel. A inferiorização dos negros a partir do racismo estrutural. Revista Direito e Práxis [online]. 2018, v. 9, n. 4 [Acessado 29 Julho 2021] , pp. 2581-2589. Disponível em: <https://doi.org/10.1590/2179-8966/2018/36867>. Epub Oct-Dec 2018. ISSN 2179-8966. https://doi.org/10.1590/2179-8966/2018/36867.

BERSANI, H. (2018). Aportes teóricos e reflexões sobre o racismo estrutural no Brasil. Revista Extraprensa, 11(2),

175-196. https://doi.org/10.11606/extraprensa2018.148025.

Disponível em: https://www.revistas.usp.br/extraprensa/article/view/148025. Acesso em: 29 jul 2021.

BUJATO, Isabela Ariane e SOUZA, Eloisio Moulin de. O CONTEXTO UNIVERSITÁRIO ENQUANTO MUNDO DO TRABALHO SEGUNDO DOCENTES NEGROS: DIFERENTES EXPRESSÕES DE RACISMO E COMO ELAS ACONTECEM. REAd. Revista Eletrônica de Administração (Porto Alegre) [online]. 2020, v. 26, n. 01 [Acessado 5 Julho 2021] , pp. 210-237. Disponível em: <https://doi.org/10.1590/14132311.282.95038>. Epub 08 Maio 2020. ISSN 1413-2311. https://doi.org/10.1590/14132311.282.95038. 
DOS SANTOS, Renato Emerson. Ações afirmativas no combate ao racismo: uma análise da recente experiência brasileira de promoção de políticas públicas. Revista Quaestio Iuris, v. 11 , n. 3, p. 2101-2128, 2018. Disponível em: https://www.epublicacoes.uerj.br/index.php/quaestioiuris/article/view/30413. Acesso em 29 jul 2021.

FREIRE, Gilberto. Casa Grande \& Senzala. Ed. Global. 1ª ed. digital. 2019.

GUIMARÃES, Antonio Sérgio Alfredo. Preconceito de cor e racismo no Brasil. Revista de antropologia, v. 47, p. 9-43, 2004. Disponível em: https://www.scielo.br/j/ra/a/B8QfF5wgK3gzDNdk55vFbnB/?format=html\&stop=previous\&la ng=pt. Acesso em: 29 jul 2021

HERCULANO, Selene. O clamor por justiça ambiental e contra o racismo ambiental. Revista de gestão integrada em saúde do trabalho e meio ambiente, v. 3, n. 1, p. 01-20, 2008. Disponível em: http://www3.sp.senac.br/hotsites/blogs/InterfacEHS/wpcontent/uploads/2013/07/art-2-2008-6.pdf . Acesso em: 02 ago 2021.

JARDIM, D. B.; CALLONI, H. A Educação Ambiental Crítica e suas relações com as Ações Afirmativas. RELACult - Revista Latino-Americana de Estudos em Cultura e Sociedade, $[S . \quad$ l. $]$, v. $\quad 6, \quad 2020$. DOI: 10.23899/relacult.v6i0.1682. Disponível em: https://periodicos.claec.org/index.php/relacult/article/view/1682. Acesso em: 6 ago 2021.

JESUS, Victor de Racializando o olhar (sociológico) sobre a saúde ambiental em saneamento da população negra: um continuum colonial chamado racismo ambiental . Saúde e Sociedade [online]. 2020, v. 29, n. 2 [Acessado 29 Julho 2021], e180519. Disponível em: <https://doi.org/10.1590/S0104-12902020180519>. Epub 11 Maio 2020. ISSN 1984-0470. https://doi.org/10.1590/S0104-12902020180519.

MENEGHINI, N. Vidal, ORSINI, A. Goulart de Sena, Sousa Gonçalves, I., \& Castro Sander Morais, J. (2021). RACISMO AMBIENTAL E ACESSO À JUSTIÇA PELA VIA DOS DIREITOS: Uma reflexão sobre o desastre ambiental em Brumadinho e os desafios para a concretização da Agenda 2030. $J^{2}$ - Jornal Jurídico, 4(2), 092-108. https://doi.org/10.29073/j2.v4i2.342

NOVAES, Diva Valério; BRYAN, Newton Antonio Paciulli. Políticas nacionais de ação afirmativa e ambientais: gestão no ambiente de uma instituição de educação profissional.ETD -Educação Temática Digital, Campinas, SP, v. 17, n. 1, p. 11-26, jan./abr. 2015. ISSN 16762592. Disponível em: <https://www.fe.unicamp.br/revistas/ged/etd/article/view/6845>. Acesso em: 30 Abr. 2015.

PACHECO, Tania; FAUSTINO, Cristiane. A iniludível e desumana prevalência do racismo ambiental nos conflitos do mapa. Injustiça ambiental e saúde no Brasil. Rio de Janeiro: FIOCRUZ, p. 73-114, 2013. Disponível em: http://books.scielo.org/id/468vp/pdf/porto9788575415764.pdf\#page=70. Acesso em 03 out 2021.

PAIVA JÚNIOR, Luiz Carlos de Oliveira. O Direito ao meio ambiente ecologicamente equilibrado: da previsão constitucional à garantia de sustentabilidade. 2018. Dissertação de 
Mestrado. UFRN. Brasil. Disponível em: https://repositorio.ufrn.br/handle/123456789/26694. Acesso em: 02 ago 2021.

PIOVESAN, Flavia. Ações afirmativas da perspectiva dos direitos humanos. Cadernos de Pesquisa [online]. 2005, v. 35, n. 124 [Acessado 29 Julho 2021] , pp. 43-55. Disponível em: <https://doi.org/10.1590/S0100-15742005000100004>. Epub 10 Ago 2005. ISSN 1980-5314. https://doi.org/10.1590/S0100-15742005000100004.

PIOVESAN, Flávia. Ações afirmativas no Brasil: desafios e perspectivas. Revista Estudos Feministas, v. 16, p. 887-896, 2008. Disponível em: https://www.scielo.br/j/ref/a/JXPnmdcRhtfnnv8FQsVZzFH/?lang=pt\&format=pdf. Acesso em: 29 jul 2021.

RESENDE, Cláudia. Raça, racismo e etnicidade: conceitos pouco visíveis num contexto pouco visível. In: Actas do VI Congresso Português de Sociologia-Mundos Sociais: saberes e práticas. 2008. p. 77-95. Disponível em: http://associacaoportuguesasociologia.pt/vicongresso/pdfs/470.pdf. Acesso em 29 jul 2021.

SILVA, Lays Helena Paes. Ambiente e justiça: sobre a utilidade do conceito de racismo ambiental no contexto brasileiro. e-cadernos ces, n. 17, 2012.

SILVEIRA, Mateus. O MEIO AMBIENTE COMO DIREITO HUMANO DE TERCEIRA DIMENSÃO E A ÉTICA DA RESPONSABILIDADE NA METATEORIA DO DIREITO FRATERNO. Revista de Direito e Sustentabilidade, v. 4, n. 1, p. 130-143, 2018. Disponível em: https://core.ac.uk/download/pdf/210565584.pdf. Acesso em 29 jul 2021.

VIEIRA, Moisés Moreira. Os crimes de racismo em face do conceito sociológico de raça. 2010. http://www.publicadireito.com.br/conpedi/manaus/arquivos/anais/salvador/moises_moreira_v iera.pdf. Acesso em: 29 jul 2021. 